\title{
The accuracy of after-hour registrar computed tomography (CT) reporting in a South African tertiary teaching hospital
}

\begin{abstract}
Authors:
Juruan F. de Witt ${ }^{1}$

Stephanie Griffith-Richards ${ }^{1}$

Richard D. Pitcher ${ }^{1}$

Affiliations:

${ }^{1}$ Division of Radiodiagnosis, Department of Medical

Imaging and Clinical

Oncology, Tygerberg Hospita

and Stellenbosch University,

South Africa
\end{abstract}

\section{Correspondence to:}

Juruan de Witt

Email:

juruandewitt@gmail.com

Postal address:

PO Box 7062, Stellenbosch

7599 , South Africa

Dates:

Received: 07 Nov. 2013

Accepted: 18 Jan. 2014

Published: 16 May 2014

How to cite this article: De Witt JF, Griffith-Richards $S$, Pitcher RD. The accuracy of after-hour registrar computed tomography (CT) reporting in a South African tertiary teaching hospital. S Afr J Rad. 2014;18(1); Art. \#591, 3 pages. http://dx.doi. org/10.4102/sajr.v18i1.591

\section{Copyright:}

(C) 2014. The Authors.

Licensee: AOSIS

OpenJournals. This work

is licensed under the

Creative Commons

Attribution License.
Background: The Division of Radiodiagnosis at Tygerberg Academic Hospital, a 1384-bed tertiary training institution in Cape Town, South Africa provides a comprehensive 24-hour clinical radiology service, and has a duty registrar on-site at all times. The demand for computed tomography $(\mathrm{CT})$ imaging is increasing and plays a pivotal role in patient management.

Objectives: The purpose of this study was to determine the accuracy of after-hour registrar CT reporting, to identify possible factors that may affect the error rate, and to assess whether or not errors had any clinical impact.

Method: A set of senior registrar reports (provisional reports) issued during a 28-day period was compared with the corresponding consultant reports (final reports). Discrepancies were identified and quantified, based on their impact on patient management.

Results: The overall discrepancy rate was $8 \%$ (18 out of 225) and the overall accuracy rate was $92 \%$ (207 out of 225). The major error rate was $4 \%$ (9 out of 225$)$ and the minor error rate was also $4 \%$ (9 out of 225 ).

Conclusion: We observed that the accuracy of after-hour CT reporting by senior registrars at the Division of Radiodiagnosis at Tygerberg Hospital was on par with international standards. We investigated three factors which may have affected discrepancy rates, and only found one factor, namely the time of day, to be significant. Steps can be taken to create awareness of this fact amongst registrars, which hopefully would result in improved patient care and management.

\section{Introduction}

The Division of Radiodiagnosis at Tygerberg Academic Hospital, a 1384-bed tertiary training institution in Cape Town, South Africa provides a comprehensive 24-hour clinical radiology service, and has a duty registrar on-site at all times. The demand for computed tomography (CT) imaging is increasing amongst all referring specialties and plays a pivotal role in patient management, resulting in an ever-increasing workload on the Division of Radiodiagnosis.

On weekdays, registrars have on-site consultant supervision from 08:00 to 21:00. Over weekends and between 21:00 and 08:00 on weekdays, radiological services at the hospital are provided solely by a senior registrar, who has two or more years of clinical radiology experience. It is the prerogative of the senior registrar to seek telephonic advice from the off-site duty radiology consultant and, if necessary, to request that the consultant provide on-site assistance for an opinion on complicated cases or technical assistance with a challenging interventional procedure. CT scan reporting represents the most important after-hour work.

All weekday after-hour registrar reports are reviewed by a consultant the following morning, whilst weekend after-hour reports are reviewed on Mondays. The relevant registrar and referring clinicians are informed of any reporting errors.

The purpose of this study was to determine the accuracy of after-hour registrar CT reporting, to identify possible factors that may affect the error rate, and to assess whether or not errors had any clinical impact.

\section{Materials and methods}

A report issued by a senior registrar in the after-hour setting is referred to as a 'provisional report'. Only after review (and possible alteration) by a consultant would the 'final report' be issued. All reports are stored on PACS, the picture archiving and communication system, and can easily be viewed by clinicians. 
A set of senior registrar reports (provisional reports) issued during a 28-day period was collected after institutional ethics review board approval. These reports were compared with the corresponding consultant reports (final reports). Studies included trauma-related investigations (CT imaging of the brain, cervical spine, chest, abdomen, pelvis and vascular system) and medical investigations (CT imaging of the brain, chest and abdomen). Any discrepancy in interpretation was identified and quantified. Errors were classified as either major errors or minor errors. Examples of major errors include: fractures not identified, vascular injuries not identified, major organ injuries not identified, no mention made of cerebral oedema, et cetera. ${ }^{1,2,3,4,5,6}$ Examples of minor errors include: incidental benign lesions not identified or mentioned (such as cysts in various organs), incorrect classification (e.g. fracture or laceration classification) which did not change the management of the patient, minor fractures not identified (whilst mention of major fractures was made), et cetera. ${ }^{1,2,3,4,5,6}$

Our rationale for quantifying errors (major vs minor) was based on their impact on patient management. It is easy to acknowledge that a major misinterpretation could result in major mismanagement of the patient. When one considers Box 1, one can appreciate why such mismanagement could result in devastating consequences. For example, when no mention is made of cerebral oedema, the swelling may progress to herniation and eventually death. Similarly, by not recognising significant fractures, the patient may develop infection, haemorrhage or even paralysis. Missed arterial and major organ injuries may continue to haemorrhage, leading to anaemia, organ failure and ultimately death.

A literature search was performed in order to determine whether similar research had been done. Five relevant publications of research performed at similar international institutions were reviewed - our results were compared with existing data to determine whether our error rate is acceptable and whether we should consider alternatives to current protocols in order to maximise patient benefit.

Furthermore, we determined whether any correlation existed between error rate on the one hand, and years of training, time of report and number of reports during a shift on the other.

Reports compiled by registrars who had completed the Fellowship of the College of Radiology, South Africa (FCRad) Part II examination, reports compiled by junior registrars, and reports not considered due to technical factors met the exclusion criteria. During the 28-day period a total of 372 after-hour CT investigations were performed. Of these investigations' reports, 147 met the exclusion criteria and were not considered, whilst 225 reports were considered for statistical analysis. Table 1 reflects the scanned body regions and referring disciplines.

\section{Results}

The overall discrepancy rate was $8 \%$ (18 out of 225 ) and the overall accuracy rate was $92 \%$ (207 out of 225). The major error rate was $4 \%$ (9 out of 225) and the minor error rate was also $4 \%$ (9 out of 225 ).

Table 2 represents the statistical breakdown of the three factors under investigation, namely time of report, number of reports during a shift and years of registrar training.

We utilised a 95\% confidence interval.

\section{Discussion}

The reviewed literature revealed discrepancy rates ranging from $0.9 \%$ to $25 \%$. $^{1,2,4,5,7}$ The discrepancy rate at Tygerberg Hospital (8\%) was considered favourable when compared with a similar training institution (17.1\%) with almost identical socio-economical parameters and patient profile (i.e. resource-limited environment within the same developing country). ${ }^{7}$ When compared with well-resourced environments (i.e. developed countries), where the discrepancy rates ranged from $0.9 \%-25 \%$, our results were regarded as acceptable.

We found it somewhat surprising that significantly more errors occurred during the day shift (08:00-21:00) than

BOX 1: Major errors encountered.

No mention made of cerebral oedema
Missed significant fracture
Missed arterial injury
Missed major organ injury
Missed subarachnoid haemorrhage
Missed infarction

TABLE 1: Scanned body regions and referring disciplines.

\begin{tabular}{lllll}
\hline $\begin{array}{l}\text { Referring } \\
\text { discipline }\end{array}$ & $\begin{array}{l}\text { Head } \pm \\
\text { C-spine }\end{array}$ & $\begin{array}{l}\text { Chest } \pm \\
\text { abdomen }\end{array}$ & Vascular & Total \\
\hline Surgical & 124 & 37 & 20 & 181 \\
Medical & 31 & 8 & 5 & 44 \\
\hline Total & $\mathbf{1 5 5}$ & $\mathbf{4 5}$ & $\mathbf{2 5}$ & $\mathbf{2 2 5}$ \\
\hline
\end{tabular}

TABLE 2: Statistical breakdown of factors under investigation.

\begin{tabular}{llll}
\hline Factors & Error rate & $\begin{array}{l}\text { Pearson Chi- } \\
\text { square }\end{array}$ & $\begin{array}{l}\text { Fisher exact, } \\
\text { two tailed }\end{array}$ \\
\hline $\begin{array}{l}\text { Time of report } \\
\text { 08:00-21:00 }\end{array}$ & $\begin{array}{l}17.07 \% \text { (7 out of } 41) \\
\text { 21:00-08:00 }\end{array}$ & 0.01788 & 0.02675 \\
Shift work load & $5.98 \%$ (11 out of 184$)$ & & \\
$<10$ & $11.76 \%$ (2 out of 17$)$ & 0.55179 & 0.63270 \\
$\geq 10$ & $7.69 \%(16$ out of 208$)$ & & \\
$\begin{array}{l}\text { Registrar seniority } \\
\text { 4th year }\end{array}$ & $12.09 \%$ (11 out of 91$)$ & 0.06252 & 0.07996 \\
2nd and 3rd year & $5.22 \%$ (7 out of 134$)$ & & \\
\hline
\end{tabular}


during the night shift (21:00-08:00). Possible explanations include the following:

- Emergency cases (stable patients requiring CT imaging as soon as possible) enjoy priority over urgent cases (stable patients who, in the opinion of the referring clinician, need CT imaging within 24 hours), resulting in urgent cases only being scanned the following morning. The high frequency of trauma-related emergency cases conditions registrars to be vigilant regarding certain crucial findings, thereby minimising discrepancies. On the other hand, urgent cases generally tend to be acute or chronic with loaded co-morbidity. It is this comorbidity that introduces a time-consuming component to interpretation and reporting and contributes to the overall complexity of the study.

- Registrars may experience a false sense of security during daytime. Our belief is that a registrar would be more confident in issuing a report at a time of day when a consultant is more readily available. Should a discrepancy arise (for example when a clinician queries the validity of a report), the process of contacting a consultant who would then review the case and offer his or her opinion would be less cumbersome. As inappropriate as it may seem, registrars perceive the processes of contacting consultants who are 'awake' and therefore more readily available, and 'unlikely to be awake' and therefore not readily available, differently.

Fourth-year registrars appeared to be more likely to make errors when compared with 2nd-year and 3rd-year registrars. However, a larger sample size would be necessary to confirm this trend. Possible explanations may be that:

- a more senior registrar would take responsibility of a more complex case

- senior registrars who are preparing for their final examinations are more sensitive to subtle pathology, thereby increasing the likelihood of overcalling certain findings.

The number of investigations during a shift played no statistical role in the likelihood of error occurrence. Possible explanations include the following:

- The rate at which scans can physically be performed on a 6-slice CT scanner, compared with the time required to report on the scans, is manageable for a senior registrar at Tygerberg Hospital. However, there are other training institutions in South Africa with a significantly more demanding workload, where the number of investigations performed (on more than one CT scanner) is likely to affect accuracy rate.
- The effect that lack of sleep has on report discrepancy rate appears to be insignificant. Senior registrars at Tygerberg Hospital are offered the privilege of a 'post-call' day, which may provide some incentive regarding the timely issuing of reports, as the assurance of total removal from the clinical milieu may be comforting.

\section{Conclusion}

We observed that the accuracy of after-hour CT reporting by senior registrars in the Division of Radiodiagnosis at Tygerberg Hospital was on par with international standards. We investigated three factors which may have affected discrepancy rates, and only found the time of day to be significant.

Steps can be taken to create awareness of this fact amongst registrars, which hopefully would result in improved patient care and management.

\section{Acknowledgements Competing interests}

The authors declare that they have no financial or personal relationship(s) that may have inappropriately influenced them in writing this article.

\section{Authors' contributions}

J.F.d.W. (Tygerberg Hospital and Stellenbosch University) was solely responsible for the manuscript, whilst S.G.-R. (Tygerberg Hospital and Stellenbosch University) and R.D.P. (Tygerberg Hospital and Stellenbosch University) acted as supervisors.

\section{References}

1. Briggs $\mathrm{RH}$, Rowbotham $\mathrm{E}$, Johnstone $\mathrm{AL}$, et al. Provisional reporting of polytrauma CT by on-call radiology registrars. Is it safe? Clin Radiol. 2010;65:616-622. http:// dx.doi.org/10.1016/j.crad.2010.04.010

2. Miyakoshi A, Nguyen QT, Cohen WA, et al. Accuracy of preliminary interpretation of neurologic CT examinations by on-call radiology residents and assessment of patient outcomes at a level I trauma center. J Am Coll Radiol. 2009;6:864-870. http://dx.doi.org/10.1016/j.jacr.2009.07.021

3. Cooper VF, Goodhartz LA, Nemcek AA, et al. Radiology resident interpretations of on-call imaging studies: The incidence of major discrepancies. Acad Radiol. 2008;15:1198-1204. http://dx.doi.org/10.1016/j.acra.2008.02.011

4. Lal NR, Murray UM, Eldevik OP, et al. Clinical consequences of misinterpretations of neuroradiologic CT scans by on-call radiology residents. Am J Neuroradiol. 2000;21:124-129.

5. Roszler MH, McCarroll KA, Rashid T, et al. Resident interpretation of emergency computed tomographic scans. Invest Radiol. 1991;26:374-376. http://dx.doi. org/10.1097/00004424-199104000-00016

6. Hillier JC, Tattersall DJ, Gleeson FV. Trainee reporting of computed tomography examinations: Do they make mistakes and does it matter? Clin Radiol. 2004;59:159-162. http://dx.doi.org/10.1016/S0009-9260(03)00309-X

7. Terreblanche $O D$, Andronikou $S$, Hlabangana LT, et al. Should registrars be reporting after-hours CT scans? A calculation of error rate and the influencing factors in South Africa. Acta Radiol. 2012;53:61-68. http://dx.doi.org/10.1258/ ar.2011.110103 